\title{
Separation and determination of four artificial sweeteners and citric acid by high-performance anion-exchange chromatography
}

\author{
Qing-chuan Chen ${ }^{a}$, Shi-fen Mou ${ }^{a} *$, Ke-na Liu ${ }^{a}$, Zu-ying Yang ${ }^{b}$, Zhe-ming Ni ${ }^{a}$

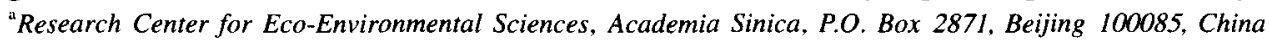 \\ ${ }^{\mathrm{h}}$ Institute of Food Safety Control and Inspection, Ministry of Public Health, Beijing 100021, China
}

Received 22 October 1996; revised 23 December 1996; accepted 13 January 1997

\begin{abstract}
A high-performance anion-exchange chromatographic method for the simultaneous separation and determination of four artificial sweeteners (sodium saccharin, aspartame, sodium cyclamate and acesulfame-K) and citric acid in a single injection is proposed. The separation was performed by an anion-exchange gradient program and determination by ultraviolet absorbance detection for sodium saccharin, aspartame, acesulfame- $\mathrm{K}$ in combination with conductivity detection for sodium saccharin, sodium cyclamate, acesulfame- $\mathrm{K}$ as well as citric acid in series. Good linearities between the concentrations of all analytes and relevant peak area responses were achieved over the range $2-100 \mu \mathrm{g} / \mathrm{ml}$. The detection limits (signal-to-noise ratio 3:1) were $0.019 \mu \mathrm{g} / \mathrm{ml}$ for sodium saccharin, $0.035 \mu \mathrm{g} / \mathrm{ml}$ for aspartame, $0.044 \mu \mathrm{g} / \mathrm{ml}$ for acesulfame- $\mathrm{K}$ by ultraviolet absorbance detection and $0.26 \mu \mathrm{g} / \mathrm{ml}$ for sodium saccharin, $0.16 \mu \mathrm{g} / \mathrm{ml}$ for sodium cyclamate, $0.23 \mu \mathrm{g} / \mathrm{ml}$ for acesulfame$\mathrm{K}$ and $0.22 \mu \mathrm{g} / \mathrm{ml}$ for citric acid by conductivity detection. The method has been successfully applied to the determination of the four sweeteners and citric acid in drinks and powdered tabletop sweeteners, and the average recoveries for various samples ranged from 93 to $107 \%$.
\end{abstract}

Keywords: Artificial sweeteners; Food analysis; Citric acid; Saccharin; Aspartame; Cyclamate; Acesulfame-K

\section{Introduction}

Artificial sweeteners are widely used in the food, beverage, confectionary and pharmaceutical industries throughout the world. Consumers select lowcalorie foods added with artificial sweeteners to decrease or control calorie intake and thus body mass and to aid control of certain health or medical conditions such as diabetes and hypoglycemia. The global consumption of artificial sweeteners has been increasing rapidly since the mid-1970s $[1,2]$.

The most common artificial sweeteners including

\footnotetext{
${ }^{*}$ Corresponding author.
}

sodium saccharin, aspartame, sodium cyclamate and acesulfame- $K$ are all used in the majority of developed countries and China (the structures of four sweeteners and citric acid are illustrated in Fig. 1). Although sodium saccharin is the oldest artificial sweetener that has been used as a sugar substitute for almost a century, the strictest restriction is placed on its usage owing to its potential toxicity and its acceptable daily intake (ADI) value formulated by the World Health Organization (WHO) is the lowest among the four sweeteners [1]. Sodium cyclamate is banned in the USA, while its usage is permitted in Europe and China [1-3]. Aspartame is considered as the safest artificial sweetener nowadays, and has 
<smiles>O=C1c2ccccc2S(=O)(=O)N1[Na]</smiles>

Sodium saccharin

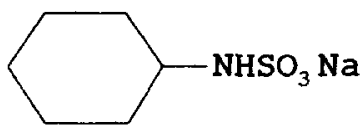

Sodium cyclamate<smiles>O=C(O)CC(O)(CC(=O)O)C(=O)O</smiles><smiles>CC(=O)C(Cc1ccccc1)C(N)C(=O)O</smiles>

\section{Aspartame}<smiles>[X]N1SOC(C)=CC1=O</smiles>

\section{Acesulfame-K}

\section{Citric acid}

Fig. 1. Structures of four sweeteners and citric acid.

been the most popular sweetener in over 75 countries. These sweeteners may be used separately or in combination with other sweeteners, and the latter is becoming increasingly popular in recent years owing to technical, health and commercial advantages [1]. In addition, citric acid has been occasionally used together with these sweeteners in foods to mask bitterness or improve their tastes.

High-performance liquid chromatography (HPLC) has been the most popular choice for the determination of artificial sweeteners. Many methods have been developed for individual sweeteners, but relatively few reports [4-15] described methods capable of simultaneously analyzing several sweeteners. Additionally, the lack of ultraviolet chromophore in the sodium cyclamate molecule makes its determination very difficult using the common HPLC-UV detection mode. Some complicated and time-consum- ing pre- or post-column derivatization and other specific procedures $[4,8,10,13,16-20]$, such as ionpair extraction, were necessary for the absorbance detection of sodium cyclamate in HPLC. Fortunately, high-performance ion chromatography (HPIC) offers an attractive alternative to these HPLC methods. Two procedures $[21,22]$ for determining sodium saccharin by high-performance anion-exchange chromatography were developed. Recently, the present authors [23] also proposed a high-performance ionexclusion chromatography coupled with UV detection for the determination of sodium saccharin. Sodium cyclamate could be determined by nonsuppressed anion-exchange chromatography [24]. Biemer [25] proposed two determination methods, one for sodium cyclamate separately and another for sodium saccharin along with acesulfame- $K$ simultaneously. All these ion chromatographic methods, 
except the present authors', adopted anion-exchange mechanisms and conductivity detection modes that are most typical in ion chromatography. Other methods such as capillary electrophoresis (CE)/ micellar electrokinetic chromatography (MEKC) can also be used for simultaneous determination of artificial sweeteners; this aspect of application has been reviewed by Lindeberg $[26,27]$. To our knowledge, the method for determining aspartame using ion chromatography has not been reported. In this paper, a new method for simultaneous determination of four artificial sweeteners and citric acid by using high-performance anion-exchange chromatography is described, and several detection modes for analytes are compared. This method can be used for the routine analyses of these artificial sweeteners and citric acid in drinks and powdered tabletop sweeteners.

\section{Experimental}

\subsection{Apparatus}

A Dionex Model DX-500 ion chromatograph (Sunnyvale, CA, USA) equipped with a $50 \mu l$ sample loop, a Dionex IonPac AG4A-SC guard column $(50 \times 4 \mathrm{~mm}$ I.D.) and a Dionex IonPac AS4A-SC separation column $(250 \times 4 \mathrm{~mm}$ I.D. $)$ were used throughout. A Dionex AD20 absorbance detector and a Dionex ED40 electrochemical detector in conductivity detection mode were placed in series. The suppression was achieved by a Dionex ASRS-I anion self-regenerating suppressor (external water mode), and the working electric current was $300 \mathrm{~mA}$. The eluents flow through the absorbance detector, suppressor and electrochemical detector in turn at a rate of $1.0 \mathrm{ml} / \mathrm{min}$. All the instrument control and data collection were performed by a Dionex PeakNet chromatography workstation.

The spectrophotometric experiments were done by using a Shimadzu UV-120-02 spectrophotometer (Kyoto, Japan) with $1 \mathrm{~cm}$ quartz cells.

\subsection{Reagents}

Acesulfame-K was purchased from Hoechst (Frankfurt, Germany) and the other artificial sweeteners from Sigma (St. Louis, MO, USA). The other reagents were of analytical reagent grade or higher purity. Distilled deionized water was used throughout. The stock solutions of all the analytes (1 $\mathrm{mg} / \mathrm{ml}$ ) were prepared by dissolving appropriate amounts in water according to the official quantification forms in various foods formulated by the Chinese national standard [3], namely sodium saccharin, aspartame, sodium cyclamate, acesulfame-K and citric acid.

\subsection{Preparation of real samples}

All the samples including two powdered tabletop sweeteners (Samples A and B), three fruit juice drinks (Samples C, D and E) and one carbonated drink (Sample F) were purchased from the local market. $30 \mathrm{mg}$ of the solid samples (A and B) were directly dissolved in water and diluted to $25 \mathrm{ml}$. The fruit juice samples were directly diluted with water. The carbonated beverage sample was degassed in an ultrasonic water bath for $5 \mathrm{~min}$ at room temperature to remove carbon dioxide gas before diluting with water. The dilution factors were 1:10 for Samples C and $\mathrm{F}$ (for determination of sodium saccharin) and 1:50 for Samples D, E and F (for determination of sodium cyclamate and citric acid). Finally, sample diluted solutions $(50 \mu \mathrm{l})$ were injected after filtering through a $0.2-\mu \mathrm{m}$ Gelman filter (Acrodisc CR PTFE).

\subsection{Analytical conditions}

The anion-exchange separation was performed by a gradient program which consisted of two eluents: $1.0 \mathrm{mmol} / 1 \mathrm{Na}_{2} \mathrm{CO}_{3}(\mathrm{E} 1)$ and $12.5 \mathrm{mmol} / 1 \mathrm{Na}_{2} \mathrm{CO}_{3}$ (E2). The quantification was achieved by conductivity detection and UV detection in which a wavelength-switching technique was used. The gradient program is listed in Table 1 . When the detection wavelength was switched to $206 \mathrm{~nm}$ from $190 \mathrm{~nm}$ at $6.00 \mathrm{~min}$ of run time, the absorbance offset was set to "on" to maintain a relatively plain baseline. It needed about $10 \mathrm{~min}$ for equilibration prior to another injection. In this study, the peak area measurements for all calculations were chosen. 
Table 1

The gradient program

\begin{tabular}{lrrlll}
\hline $\begin{array}{l}\text { Time } \\
(\mathrm{min})\end{array}$ & $\begin{array}{l}\text { E1 } \\
(\%)\end{array}$ & $\begin{array}{l}\text { E2 } \\
(\%)\end{array}$ & $\begin{array}{l}\text { Wavelength } \\
(\mathrm{nm})\end{array}$ & $\begin{array}{l}\text { Conductivity } \\
\text { offset }\end{array}$ & $\begin{array}{l}\text { Absorbance } \\
\text { offset }\end{array}$ \\
\hline 0 & 100 & 0 & 190 & On \\
4.50 & 100 & 0 & 190 & \\
5.50 & 0 & 100 & 190 & \\
6.00 & 0 & 100 & 206 & \\
28.00 & 0 & 100 & 206 & \\
28.10 & 100 & 0 & 190 & & \\
\hline
\end{tabular}

\section{Results and discussion}

\subsection{Choice of separation system}

From the point of view of structures (shown in Fig. 1), all the analytes exist as anionic forms in basic aqueous solutions. Hence, it is possible to separate one from another by using an anion-exchange mechanism. Preliminary experiments show that aspartame and sodium cyclamate were eluted out quickly on an IonPac AS4A-SC column by using $\mathrm{NaHCO}_{3} / \mathrm{Na}_{2} \mathrm{CO}_{3}$ or $\mathrm{Na}_{2} \mathrm{CO}_{3}$ solution as eluent. Because the conductivity response of aspartame and the UV response of sodium cyclamate were both very low, no mutual interferences for separation of the two analytes occurred. By contrast, the retention of the other analytes was much greater on the stationary phase under the same conditions, which can be explained by the hydrophobicity of sodium saccharin and acesulfame- $\mathrm{K}$ as well as the -3 charge of citrate. To avoid too long a run time, a gradient program with two concentration levels of sodium carbonate solutions was chosen. If the concentration of $\mathrm{E} 1$ was too low, the run time would be prolonged; if the concentration of El was too high, the peak of aspartame would be very near to the negative water peak resulting in an inaccurate quantification result. Therefore, $1.0 \mathrm{mmol} / \mathrm{l}$ was selected as the E1 concentration. The relationship between E2 concentrations and the retention times of the other analytes (according to conductivity detector) are shown in Fig. 2; it can be found that the retention times of three analytes decreased by increasing the E2 concentration and the decrease for citric acid was the most apparent. When the E2 concentration was 20 $\mathrm{mmol} / \mathrm{l}$, citric acid was eluted out in front of sodium saccharin which was different from the elution sequence by using the other E2 concentrations shown in Fig. 2. Because the existing form of citric acid, i.e. citrate, possesses a -3 charge in basic aqueous solution its retention time depends greatly on eluent concentration compared with sodium saccharin and acesulfame-K, which exist as monovalent anions under the same condition [28]. When the E2 concentration was 15 to $20 \mathrm{mmol} / \mathrm{l}$, the peaks of sodium saccharin and citric acid were partially or completely overlapping. When the E2 concentration was 10 to $12.5 \mathrm{mmol} / \mathrm{l}$, the baseline separation of all the three analytes was achieved. So $12.5 \mathrm{mmol} / \mathrm{l}$ was chosen as the E2 concentration owing to a relatively shorter run time. Organic modifier was added to E2 to improve the peak shapes. When E2 was $20 \mathrm{mmol} / 1$ $\mathrm{Na}_{2} \mathrm{CO}_{3}+20 \%$ methanol, the column pressure increased, and the retention times of these three analytes were $11.55 \mathrm{~min}$ for acesulfame-K, 12.32 min for sodium saccharin and $14.96 \mathrm{~min}$ for citric acid. That is to say, compared with the retention when $\mathrm{E} 2$ was $20 \mathrm{mmol} / 1 \mathrm{Na}_{2} \mathrm{CO}_{3}$, the retention times of acesulfame- $K$ and sodium saccharin decreased more than that of citric acid, and the elution

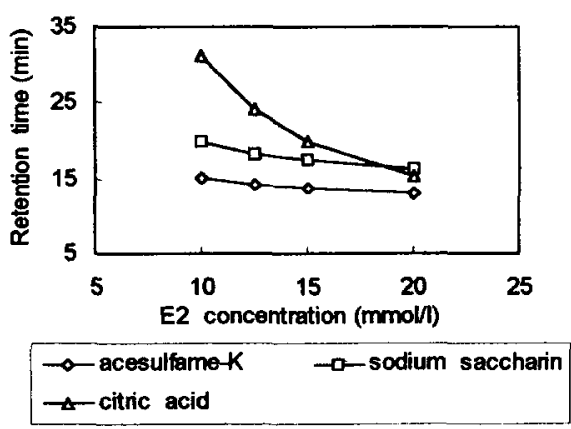

Fig. 2. Effect of $\mathrm{E} 2\left(\mathrm{Na}_{2} \mathrm{CO}_{3}\right)$ concentration on retention time of acesulfame-K, sodium saccharin and citric acid. 
order of sodium saccharin and citric acid was reversed again. All these indicated that for acesulfame- $\mathrm{K}$ and sodium saccharin, the retention mechanisms consisted of relatively stronger adsorption apart from pure ionic interaction [28]. We can also find that when the organic modifier (e.g., methanol or acetonitrile) was added to the E2 eluent, the separation of acesulfame- $\mathrm{K}$ and sodium saccharin was not satisfactory. Besides, for conductivity detection, the baseline became relatively unstable, and the system peak became greater which interfered with the quantification of acesulfame-K. By contrast, the addition of organic modifier had no influence on the ultraviolet detection. To obtain better separation and more satisfactory detection limits for conductivity detection, finally, $12.5 \mathrm{mmol} / 1$ sodium carbonate aqueous solution was preferred as E2 eluent.

\subsection{Choice of detection modes}

The most commonly used detection mode for the determination of artificial sweeteners by HPLC was UV detection. However, this mode is not suitable for the detection of sodium cyclamate and citric acid because both of them have no ultraviolet characteristic. The typical conductivity detection mode in ion chromatography is not capable for the detection of aspartame because it is converted from an anion to a neutral molecule after suppression [29]. So we decided to connect the two detection modes in series to meet the demand of simultaneous determination of all the analytes; aspartame can be detected by UV detector, sodium cyclamate and citric acid by conductivity detector, and acesulfame- $\mathrm{K}$ as well as sodium saccharin by both of the two detection methods. According to the connection order of detectors and suppressor, two possible modes exist: (1) UV detector + suppressor + conductivity detector; (2) suppressor + conductivity detector +UV detector. In further study, the two connection modes were compared.

The results obtained were the same by using conductivity detection in either connection mode. But for UV detection, the results obtained were very different. The effects of UV detection wavelength by using the two modes on peak area responses are illustrated in Fig. 3, the response curves of all the three analytes possessing UV chromophores are

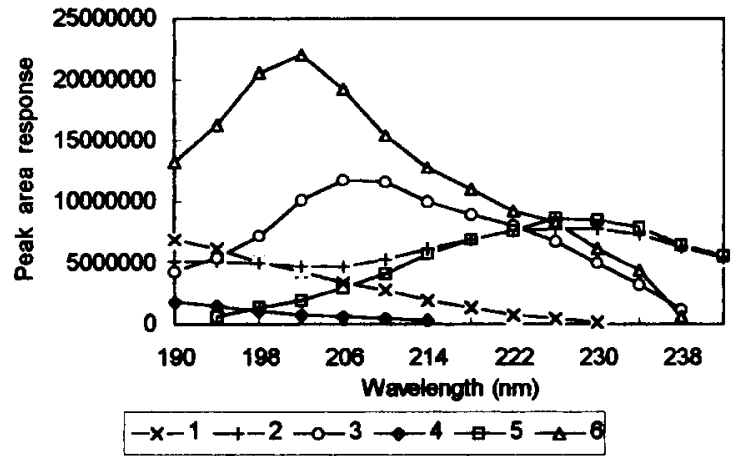

Fig. 3. Effect of wavelength on peak area response. The concentrations of analytes were all at $50 \mu \mathrm{g} / \mathrm{ml}$. The first connection mode: 1 =aspartame; 2 =acesulfame-K; $3=$ sodium saccharin. The second connection mode: $4=$ aspartame; $5=$ acesulfame-K; $6=$ sodium saccharin.

different for the two connection modes. Further, the maximum absorption wavelength of sodium saccharin changes. All the phenomena revealed that there might be some possible changes in the existing forms of these analytes after suppression, though the details were not clear (experiment showed that after suppression, the $\mathrm{pH}$ values of $\mathrm{E} 1$ and $\mathrm{E} 2$ were changed to 4.72 and 4.30 from 10.47 and 11.39 , respectively). At the relevant maximum absorption wavelength of analytes for the two connection modes (190 $\mathrm{nm}$ for aspartame and $226 \mathrm{~nm}$ for acesulfame-K by using both modes, $206 \mathrm{~nm}$ and $202 \mathrm{~nm}$ for sodium saccharin by using the first connection mode and the second, respectively), the signals of sodium saccharin and acesulfame- $K$ increase while the signal of aspartame decreases when using the second connection mode. From Fig. 4, we can find that the UV absorbance of E1 and E2 decreased greatly after suppression (water as blank solution). We can conclude that under some conditions it may be an attractive alternative to connect a suppressor prior to a UV detector which may reduce the UV background absorbance along with improving the signal responses of some target analytes. Because the UV signal of aspartame by using the second connection mode was very low and the detection sensitivity of sodium saccharin and acesulfame- $K$ by using either connection mode could meet the demand of routine analysis of real samples, in this study, the first connection mode was adopted. To obtain as strong a 

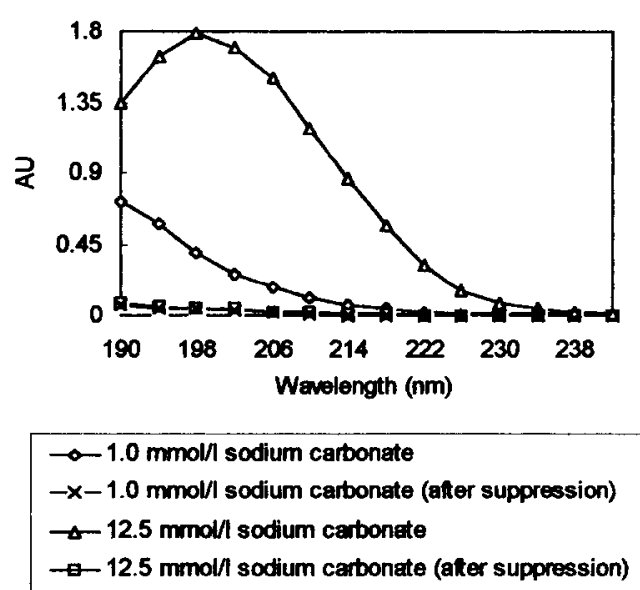

Fig. 4. Ultraviolet absorption curves of eluents. Measurement was performed by using a Shimadzu UV-120-02 spectrophotometer with $1 \mathrm{~cm}$ quartz cells.

signal as possible, a wavelength switching technique was used; $190 \mathrm{~nm}$ was chosen for detecting aspartame, and $206 \mathrm{~nm}$ for detecting sodium saccharin and acesulfame-K. The latter wavelength was chosen rather than $226 \mathrm{~nm}$ to make the signal for sodium saccharin stronger because the restriction of sodium saccharin content in foods is the strictest among all artificial sweeteners. Because the peaks of acesulfame- $\mathrm{K}$ and sodium saccharin are very near, to avoid inaccurate quantification results caused by baseline change, another wavelength switching program (from $190 \mathrm{~nm}$ to $226 \mathrm{~nm}$, then to $206 \mathrm{~nm}$ ) is not used. Under the adopted experimental conditions, the chromatograms of a standard solution where the concentrations of all the analytes are $50 \mu \mathrm{g} / \mathrm{ml}$ are shown in Fig. 5a,b.

\subsection{Linearity, precision and detection limits}

Under the optimum experimental conditions, the analytes all showed good linearities in the range $2-100 \mu \mathrm{g} / \mathrm{ml}$. For UV detection, the correlation coefficients were $0.9982,0.9999$ and 0.9998 for aspartame, acesulfame- $K$ and sodium saccharin, respectively. For conductivity detection, the correlation coefficients were $0.9991,0.9997,0.9999$ and 0.9998 for sodium cyclamate, acesulfame- $K$, sodium saccharin and citric acid, respectively. The relative standard deviation (R.S.D.) values for seven repli- (a)

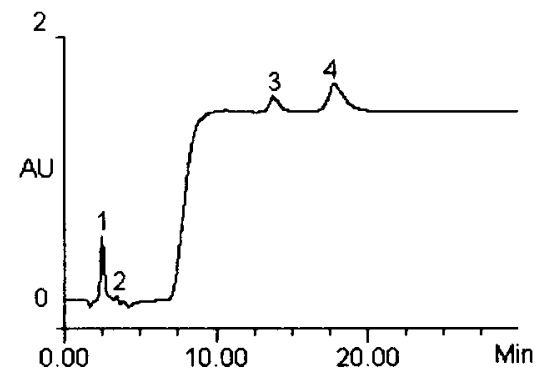

(b)

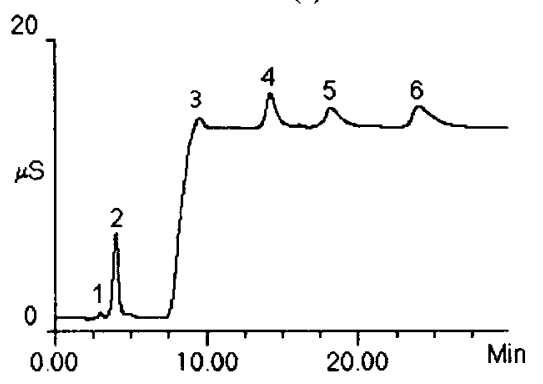

(c)

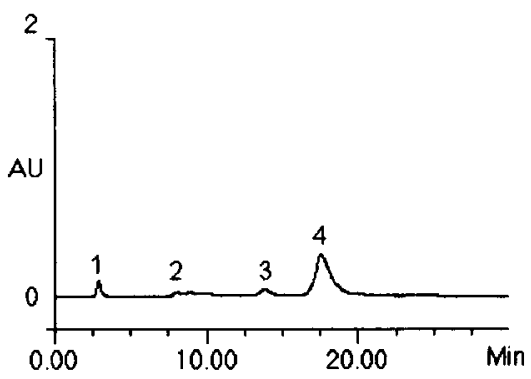

Fig. 5. Chromatograms of standard solution where the concentrations of all analytes were at $50 \mu \mathrm{g} / \mathrm{ml}$. The first connection mode of detectors: (a) UV detection mode, peaks: 1=aspartame; 2 =sodium cyclamate; $3=$ acesulfame-K; $4=$ sodium saccharin. (b) Conductivity detection mode, peaks: $1=$ aspartame; $2=$ sodium cyclamate; $3=$ system peak; 4=acesulfame-K; 5=sodium saccharin; $6=$ citric acid. The second connection mode of detectors: (c) UV detection mode, peaks: $1=$ aspartame; $2=$ system peak; $3=$ acesulfame-K; 4=sodium saccharin. Detailed analytical conditions as in the text.

cated analyses of a standard solution where the concentrations of all the analytes were $50 \mu \mathrm{g} / \mathrm{ml}$ were also calculated. For UV detection, the R.S.D. values for aspartame, acesulfame- $K$ and sodium saccharin were $1.72,1.68$ and $0.84 \%$, respectively. 
For conductivity detection, the R.S.D. values for sodium cyclamate, acesulfame-K, sodium saccharin and citric acid were 1.38, 1.34, 1.10 and $1.25 \%$, respectively. The detection limits (signal-to-noise ratio 3:1) were calculated as $0.035 \mu \mathrm{g} / \mathrm{ml}$ for aspartame, $0.044 \mu \mathrm{g} / \mathrm{ml}$ for acesulfame-K, as well as $0.019 \mu \mathrm{g} / \mathrm{ml}$ for sodium saccharin by UV detection, and as $0.16 \mu \mathrm{g} / \mathrm{ml}$ for sodium cyclamate, $0.23 \mu \mathrm{g} /$

Table 2

Analysis of real samples

\begin{tabular}{|c|c|c|c|c|c|c|}
\hline \multirow[t]{2}{*}{ Sample } & \multirow[t]{2}{*}{ Analyte } & \multicolumn{2}{|c|}{ Content $^{\mathrm{a}}(\mathrm{mg} / \mathrm{g}$ or $\mathrm{mg} / \mathrm{ml})$} & \multirow[t]{2}{*}{ Added (mg) } & \multicolumn{2}{|l|}{ Recovery $(\%)^{\mathrm{b}}$} \\
\hline & & UV detection & Conductivity detection & & UV detection & Conductivity detection \\
\hline A & $\begin{array}{l}\text { Aspartame } \\
\text { Sodium cyclamate } \\
\text { Acesulfame-K } \\
\text { Sodium saccharin } \\
\text { Citric acid }\end{array}$ & $\begin{array}{l}36.85 \pm 1.28 \\
\mathrm{ND} \\
\mathrm{ND}\end{array}$ & $\begin{array}{l}\text { ND } \\
\text { ND } \\
\text { ND } \\
\text { ND }\end{array}$ & & & \\
\hline B & $\begin{array}{l}\text { Aspartame } \\
\text { Sodium cyclamate } \\
\text { Acesulfame-K } \\
\text { Sodium saccharin } \\
\text { Citric acid }\end{array}$ & $\begin{array}{l}34.26 \pm 1.17 \\
\mathrm{ND} \\
\mathrm{ND}\end{array}$ & $\begin{array}{l}\text { ND } \\
\text { ND } \\
\text { ND } \\
\text { ND }\end{array}$ & & & \\
\hline $\begin{array}{l}\text { C (wild } \\
\text { grape } \\
\text { nectar) }\end{array}$ & $\begin{array}{l}\text { Aspartame } \\
\text { Sodium cyclamate } \\
\text { Acesulfame-K } \\
\text { Sodium saccharin } \\
\text { Citric acid }\end{array}$ & $\begin{array}{l}0.2531 \pm 0.0060 \\
\text { ND } \\
\text { ND }\end{array}$ & $\begin{array}{l}\text { ND } \\
\text { ND } \\
\text { ND } \\
\text { ND }\end{array}$ & & & \\
\hline $\begin{array}{l}\mathrm{D} \text { (lemon } \\
\text { juice) }\end{array}$ & $\begin{array}{l}\text { Aspartame } \\
\text { Sodium cyclamate } \\
\text { Acesulfame-K } \\
\text { Sodium saccharin } \\
\text { Citric acid }\end{array}$ & $\begin{array}{l}0.3732 \pm 0.0130 \\
\text { ND } \\
\text { ND }\end{array}$ & $\begin{array}{l}\text { ND } \\
\text { ND } \\
\text { ND } \\
3.1305 \pm 0.0301\end{array}$ & & & \\
\hline $\begin{array}{l}\text { E (kiwi } \\
\text { fruit }\end{array}$ & Aspartame & $0.3112 \pm 0.0095$ & & $\begin{array}{l}0.50 \\
1.25\end{array}$ & $\begin{array}{l}96.85 \pm 3.79 \\
96.84 \pm 1.45\end{array}$ & \\
\hline nectar) & Sodium cyclamate & & ND & $\begin{array}{l}0.50 \\
1.25\end{array}$ & & $\begin{array}{l}105.39 \pm 5.06 \\
101.84 \pm 2.02\end{array}$ \\
\hline & Acesulfame-K & ND & ND & $\begin{array}{l}0.50 \\
1.25\end{array}$ & $\begin{array}{l}98.27 \pm 1.28 \\
98.62 \pm 1.17\end{array}$ & $\begin{array}{r}95.80 \pm 1.36 \\
104.07 \pm 1.29\end{array}$ \\
\hline & $\begin{array}{l}\text { Sodium saccharin } \\
\text { Citric acid }\end{array}$ & ND & $\begin{array}{l}\text { ND } \\
1.9769 \pm 0.0172\end{array}$ & $\begin{array}{l}0.50 \\
1.25 \\
0.50 \\
1.25\end{array}$ & $\begin{array}{r}94.08 \pm 1.86 \\
101.72 \pm 1.65\end{array}$ & $\begin{array}{r}96.97 \pm 2.47 \\
103.86 \pm 1.62 \\
97.85 \pm 3.15 \\
99.72 \pm 2.76\end{array}$ \\
\hline $\mathbf{F}$ & Aspartame & ND & & $\begin{array}{l}0.50 \\
1.25\end{array}$ & $\begin{array}{l}99.75 \pm 3.55 \\
95.42 \pm 0.66\end{array}$ & \\
\hline & Sodium cyclamate & & $1.4858 \pm 0.0327$ & $\begin{array}{l}0.50 \\
1.25\end{array}$ & & $\begin{array}{r}104.65 \pm 4.55 \\
93.68 \pm 2.04\end{array}$ \\
\hline & Acesulfame-K & ND & ND & $\begin{array}{l}0.50 \\
1.25\end{array}$ & $\begin{array}{r}94.10 \pm 1.85 \\
100.00 \pm 1.64\end{array}$ & $\begin{array}{r}96.45 \pm 3.30 \\
103.34 \pm 1.88\end{array}$ \\
\hline & Sodium saccharin & $0.0443 \pm 0.0007$ & $0.0445 \pm 0.0013$ & $\begin{array}{l}0.50 \\
1.25\end{array}$ & $\begin{array}{r}100.00 \pm 1.56 \\
97.08 \pm 1.00\end{array}$ & $\begin{array}{r}106.70 \pm 2.95 \\
99.44 \pm 1.86\end{array}$ \\
\hline & Citric acid & & $1.1376 \pm 0.0162$ & $\begin{array}{l}0.50 \\
1.25\end{array}$ & & $\begin{array}{l}96.35 \pm 3.75 \\
98.70 \pm 2.02\end{array}$ \\
\hline
\end{tabular}

${ }^{\text {a }}$ Average of five determinations \pm standard deviation, $\mathrm{mg} / \mathrm{g}$ for solid samples (A and $\mathrm{B}$ ) and $\mathrm{mg} / \mathrm{ml}$ for the other samples.

${ }^{b}$ Average of five determinations \pm standard deviation.

ND=not detected. 
$\mathrm{ml}$ for acesulfame-K, $0.26 \mu \mathrm{g} / \mathrm{ml}$ for sodium saccharin, as well as $0.22 \mu \mathrm{g} / \mathrm{ml}$ for citric acid by conductivity detection. We can find that for acesulfame- $K$ and sodium saccharin, the detection limits obtained by UV detection are relatively better. If the UV wavelength were switched to $226 \mathrm{~nm}$ at $6 \mathrm{~min}$ of run time, the relevant detection limits for acesulfame-K and sodium saccharin would be 0.026 and $0.034 \mu \mathrm{g} / \mathrm{ml}$, respectively. Therefore, either 206 or $226 \mathrm{~nm}$ can be used for routine analysis, according mainly to the target analyte in which the analysts are interested. Furthermore, the UV detection limits for aspartame, acesulfame- $K$ and sodium saccharin by using the above-mentioned second connection mode, for which the UV detection wavelength was switched to $202 \mathrm{~nm}$ (the maximum absorption wavelength of sodium saccharin under this condition) from $190 \mathrm{~nm}$ at $6 \mathrm{~min}$ of run time, were calculated as $0.17,0.18$ and $0.018 \mu \mathrm{g} / \mathrm{ml}$, respectively. The decrease of UV

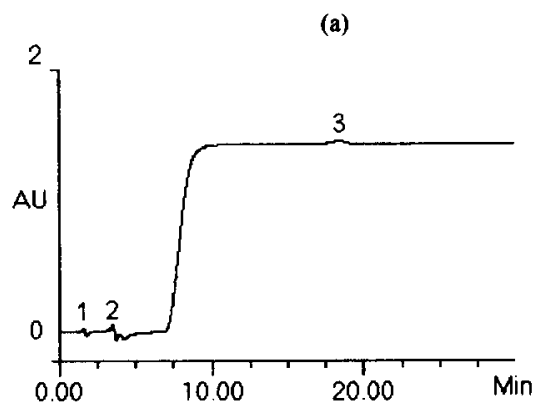

(b)

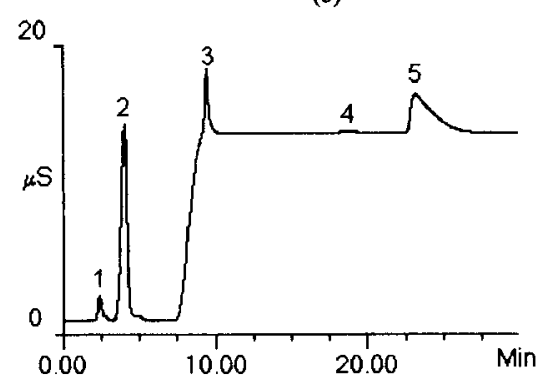

Fig. 6. Chromatograms of Sample F diluted solution (1:10). (a) UV detection mode, peaks: $1=$ unknown peak; 2 =sodium cyclamate; $3=$ sodium saccharin. (b) Conductivity detection mode, peaks: $1=$ unknown peak; $2=$ sodium cyclamate; $3=$ system peak + unknown peak; $4=$ sodium saccharin; $5=$ citric acid. Detailed analytical conditions as in the text. detection sensitivities for aspartame and acesulfame$\mathrm{K}$ can be estimated from Fig. 3, the evident improvement of the UV detection limit for sodium saccharin was not found due to the increase in baseline noise after suppression. Fig. 5c shows the chromatogram obtained by UV detector under this condition.

\subsection{Analysis of real samples}

All the samples were analysed according to the optimum experimental conditions, the results obtained are summarized in Table 2 and the chromatograms of Sample F diluted solution shown in Fig. 6. The results of sodium saccharin in Sample $F$ were inconsistent with that found by ion-exclusion chromatography [23] which was $0.0458 \mathrm{mg} / \mathrm{ml}$. Spike studies were carried out using Samples E and F, and each analyte was spiked into $25 \mathrm{ml} \mathrm{1:50} \mathrm{sample}$ diluted solution. For Sample F, the spiked recovery of sodium saccharin was carried out by using $25 \mathrm{ml}$ 1:10 sample diluted solution. The results also shown in Table 2 were satisfactory.

\section{Conclusions}

A high-performance anion-exchange chromatographic method for the separation and determination of four artificial sweeteners and citric acid in a single run was developed. This method utilized two detectors which were connected in series and the wavelength switching technique to improve the detection sensitivity. The method has been applied to the analysis of real samples with satisfactory results.

\section{Acknowledgments}

The authors are grateful to the Dionex Corporation for financial support.

\section{References}

[1] M. Mathlouthi and C. Berssan, in R. Khan (Editor), LowCalorie Foods and Food Ingredients, Blackie, London, 1993, Ch. 8 . 
[2] R. Newsome, in A.M. Altschul (Editor), Low-Calorie Foods Handbook, Marcel Dekker, New York, 1993, Ch. 8.

[3] National standard of the People's Republic of China, GB 2760-86, Hygienic standards for food additives in use, 1986.

[4] A. Herrmann, E. Damawandi and M. Wagmann, J. Chromatogr., 280 (1983) 85.

[5] C.J. Argoudelis, J. Chromatogr., 303 (1984) 256.

[6] T.A. Tyler, J. Assoc. Off. Anal. Chem., 67 (1984) 745.

[7] M. Veerabhadrarao, M.S. Narayan, O. Kapur and C.S. Sastry, J. Assoc. Off. Anal. Chem., 70 (1987) 578.

[8] J.F. Lawrence and C.F. Charbonneau, J. Assoc. Off. Anal. Chem., 71 (1988) 934.

[9] J. Prodolliet and M. Bruelhart, J. Assoc. Off. Anal. Chem., 76 (1993) 268.

[10] J.F. Lawrence, Int. J. Environ. Anal. Chem., 38 (1990) 115.

[11] A.M. Di Pietra, V. Cavrini, D. Bonazzi and L. Benfenati, Chromatographia, 30 (1990) 215.

[12] T. Moriyasu, K. Saito, M. Nakazato, F. Ishikawa, K. Fujinuma and T. Nishima, Eisei Kagaku, 37 (1991) 97.

[13] J.F. Lawrence, Analyst, 112 (1987) 879.

[14] U. Zache and H. Gründing, Z. Lebensm.-Unters. Forsch., 184 (1987) 503.

[15] A. Hannisdal, Z. Lebensm.-Unters. Forsch., 194 (1992) 517.

[16] M. Nakazato, K. Saito, F. Ishikawa, K. Fujinuma, T. Moriyasu and T. Nishima, Shokuhin Eiseigaku Zasshi, 34 (1993) 248 .
[17] G. Schwedt and M. Hauck, Z. Lebensm.-Unters. Forsch., 187 (1988) 127.

[18] M. Hauck and H. Köbler, Z. Lebensm.-Unters. Forsch., 191 (1990) 322.

[19] M. Lehr and W. Schmid, Z. Lebensm.-Unters. Forsch., 192 (1991) 335 .

[20] J. Ruter and D.I.U. Raczek, Z. Lebensm.-Unters. Forsch., 194 (1992) 520.

[21] Application Note 47, Dionex Corporation, Sunnyvale, CA, 1985.

[22] D.T. Heitkemper, D.S. Jackson, L.A. Kaine, K.A. Mulligan and K.A. Wolnik, J. Chromatogr. A, 671 (1994) 323.

[23] Q.C. Chen, S.F. Mou and Q. Song, Fenxi Ceshi Xuebao, in press.

[24] D. Murawski, J. Chromatogr., 546 (1991) 351.

[25] T.A. Biemer, J. Chromatogr., 463 (1989) 463.

[26] J. Lindeberg, Food Chem., 55 (1996) 73.

[27] J. Lindeberg, Food Chem., 55 (1996) 95.

[28] J. Weiss, Ion Chromatography, VCH, Weinheim, 1995.

[29] A.E. Martell and R.M. Smith, Critical Stability Constants, Volume 5: First Supplement, Plenum Press, New York, 1982. 